\title{
A fascinação da compulsão tecnológica: sobre a racionalidade científica em Hans Jonas
}

\author{
Maurício Chiarello
}

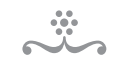

RESUMO

Em que medida a proposta de uma nova ética para a civilização tecnológica, elaborada por Hans Jonas, possuiria o condão de convocar os cientistas para o efetivo exercício de sua responsabilidade perante à natureza ameaçada? O esclarecimento, que sua obra pretende levar a termo a respeito dos crescentes perigos associados ao progresso técnico-científico, não procura fundamentalmente refrear, em caráter emergencial, a cega compulsão de aplicação tecnológica, com os perversos efeitos associados à tecnologização e à mercantilização da ciência em nossos dias? Com efeito, sua crítica da ideologia legitimadora do progresso tecnocientífico procura, em última instância, debelar o processo compulsivo de aplicações tecnológicas, considerado perverso em si mesmo, não se permitindo considerar de que outra forma o progresso tecnocientífico poderia vir a desenvolver-se, de modo a tornar-se efetivamente capaz de atender valores humanos, sociais e ambientais. A partir da explicitação dos impasses a que conduz a proposta de Jonas, respaldamo-nos nos estudos de Hugh Lacey para apresentar uma forma alternativa de estruturação das atividades científicas. Visando suplantar esses impasses, procuramos investigar em que medida o desejável acolhimento de valores morais, sociais e ambientais, por parte das práticas científicas e tecnológicas vigentes, poderia estar conjugado com uma experiência propriamente estética capaz de propiciar a abertura à alteridade e o acolhimento de valores alheios. A investigação do concurso de uma ex-

periência deste teor é realizada à luz de motivos de pensamento presentes nas obras de Theodor Adorno e Herbert Marcuse.

PalaVras-chave • Jonas. Dominação da natureza. Tecnociência. Controle. Valores. Experiência estética. Mímesis. Lacey. Adorno. Marcuse.

\section{INTRODUÇÃO}

No que concerne ao juízo relativo à tecnociência hodierna, assim como ao conceito de natureza instaurado pela ciência moderna, gostaríamos de assinalar, na obra de Hans Jonas, uma disjunção entre dois planos de argumentação que se afiguram insuficientemente articulados.

Em primeiro lugar, observamos a existência de um plano argumentativo em que a crítica incide sobre o conceito de natureza próprio da ciência moderna, o qual legitima a dominação incessante e a exploração inesgotável do objeto natural. Segundo tal 
conceito instaurado pela ciência moderna, a natureza é apreendida como uma dinâmica de poder alheia e mesmo soberanamente indiferente ao homem (o gnosticismo cristão está nas origens da ciência moderna para Jonas), e o cosmo que o engloba é visto como objeto passível de manipulação e controle posto à disposição do sujeito. A ciência moderna - e não só a tecnologia, seu braço armado - revela-se comprometida com esse processo de usura e desfiguração da natureza como um todo. É um plano de argumentação que se encontra em perfeita consonância com a crítica da razão instrumental elaborada por Adorno e Horkheimer (1985), crítica esta que, por sua vez, guarda grande afinidade com o pensamento heideggeriano. ${ }^{\mathbf{1}}$

Contudo, ao lado dessa vertente argumentativa na qual a crítica incide sobre o conceito de natureza instaurado pela ciência moderna, encontramos na obra de Jonas outra vertente argumentativa na qual a crítica recai, prioritariamente, sobre a húbris do poder tecnológico, que leva a humanidade a exaurir a natureza de forma inescrupulosa, indiscriminada e catastrófica. Em contraste com a vertente argumentativa anterior, a ciência não se afigura aqui comprometida com o processo em curso de exaustão e desfiguração da natureza. Ao contrário, ela se mostra não só isenta, mas até mesmo indispensável para remediar tal processo de exacerbação tecnológica, posto que só ela se mostra capaz de fornecer, ainda que sempre a posteriori, o conhecimento necessário das perturbações ocasionadas ao delicado e complexo equilíbrio dos ecossistemas e da biosfera em decorrência do emprego abusivo e indiscriminado das novas tecnologias. Mais ainda, na medida em que o desenvolvimento de novas tecnologias é um processo incessante e irrevogável, a correta regulação ou administração de nosso poderio tecnológico demandará sem cessar novos conhecimentos científicos sobre os efeitos, tanto diretos como indiretos, ocasionados pelo emprego das novas tecnologias, assim como sobre os riscos potenciais à saúde humana e ambiental que elas apresentam: "para essa nova situação, que confere ao conhecimento das consequências e, com ele, ao conhecimento científico um papel de que nunca antes se teve notícia, não fomos preparados por nenhuma doutrina de deveres; e aqui se encontra uma tarefa da teoria ética que ainda precisa ser enfrentada" (Jonas, 2006, p. 270).

No que segue, procuramos explorar cada uma dessas vertentes argumentativas com mais profundidade, delineando, ao final de cada exposição, um motivo crítico que nos parece apropriado.

1 Como lema dessa vertente argumentativa, podemos tomar a seguinte sentença: "Dreck ist die Natur. Allein die abgefeimte Kraft, die überlebt, hat Recht”. "A natureza é uma porcaria [uma coisa sem valor]. Só a força astuciosa capaz de sobreviver tem razão" (Adorno \& Horkheimer, 1985, p. 236). 
A fasginaÇÃo da Gompulsão tegnológiga...

\section{A GiÊNGIA MODERNA ENQUANTO DINÂMIGA DE PODER E DOMINAÇÃo}

Respalda este plano de argumentação a profunda afinidade existente, segundo Jonas, entre as concepções gnósticas e a cosmovisão científico-matemática da natureza consolidada pela ciência moderna. Com a destruição do cosmo clássico na modernidade, a essência do homem passa a ser incomensurável com a matéria e a existência mundana. Como observa um comentador da obra joniana, "tal como os gnósticos, o homem moderno experimenta a perda de sua essência cósmica, isto é, a perda da crença segundo a qual o valor do homem consiste em ser parte de uma totalidade" (Tibaldeo, 2012, p. 293). Seria interessante ressaltar, no entanto, que a solidão cósmica e a alienação da natureza, decorrentes do dualismo moderno de matéria e espírito, são, para Jonas, ainda mais desesperadas e radicais do que aquela das concepções gnósticas. Também o nihilismo moderno apresenta um caráter ainda mais pernicioso, porque, ao reduzir a natureza a seu caráter materialista e mecânico e ao promover uma dissociação entre os fatos e os valores (prescrevendo, assim, ao objeto natural uma neutralidade axiológica), a concepção científica moderna instaura uma indiferença perante a natureza, ao mesmo tempo em que uma natureza indiferente, que exclui a possibilidade de quaisquer compromissos éticos, ainda presentes nas concepções gnósticas. Nestas últimas, com efeito, a natureza aparece como decaída e eminentemente adversa ao espírito, o qual, sentindo horror ao orgânico, repugnância pelo corpo e aversão pelo natural, almeja sua transcendência mediante o conhecimento salvífico da gnose. Justamente porque vista como antagônica, a natureza gnóstica ainda nos concerne, encerrando por isso uma esperança de redenção que desaparece por completo em uma ordem mecânica soberanamente indiferente ao homem. Quando a natureza passa a ser entendida como dinâmica extrínseca de força e poder, a relação do ser humano com ela torna-se também uma relação de poder e controle sem termo de reconciliação.

Mutatis mutandis, a crítica feita por Jonas à tecnociência hodierna apresenta, nesse plano, o mesmo teor da elaborada por Heidegger e seus discípulos. Também nessa crítica, é em contraste com o pano de fundo comum do antigo conceito grego de techné, fundado no reconhecimento de finalidades intrínsecas à natureza, que a ciência moderna é recriminada. Na medida em que a natureza passa a ser concebida como mero material passível de ser manipulado e controlado - um reservatório, enfim, à disposição da exploração do homem -, a tecnociência moderna termina por eliminar toda referência a finalidades ou potencialidades intrínsecas à natureza.

O reconhecimento do ser natural como ser dotado de finalidades próprias conjuga-se, em Jonas, com a defesa de uma ontologia crítica do antropocentrismo cujo fulcro é o ser como corpo vivo, isto é, de uma ontologia capaz de apreender o ser como totalidade indissociável de matéria e espírito e, por isso mesmo, ser vivo. A ontologia 
proposta por Jonas é, assim, uma ontologia da vida fundamentalmente crítica da dissociação dualista entre o espírito e a matéria instaurada pela modernidade, notadamente pela ciência moderna, segundo a qual a matéria destituída de espírito é posta como mero objeto à total sujeição de um espírito destituído de corpo (incorpóreo), o sujeito. Em consequência da promoção da causalidade mecanicista na determinação dos processos naturais, dá-se a imposição da causalidade eficiente subjetiva em detrimento do reconhecimento das finalidades próprias da natureza viva. Desse modo, o espírito subjetivo faz valer seus propósitos e finalidades sobre a natureza como um todo, reduzida a mera matéria despojada de finalidade própria.

Resumidamente, poderíamos dizer que Jonas caracteriza o processo que desvitaliza o objeto natural, levado a termo pela ciência moderna, sob dois aspectos fundamentais: (1) a neutralização do objeto natural graças à destituição de uma causalidade eficiente intrínseca à natureza viva; (2) a denegação das causas finais sob alegação de superação do antropomorfismo primitivo (cf. Jonas, 2004, cap. 2, p. 35 ss.).

Consideremos, por exemplo, um aspecto fundamental do desenvolvimento da ciência moderna, o entrelaçamento entre a teoria e a prática, resultante de sua interação recíproca. Segundo Jonas, a dinâmica de interação recíproca entre a teoria e a prática intensificou-se, com o passar dos séculos, a ponto de tornar a teoria compulsivamente tecnológica e mesmo a ponto de, em nossos dias, promover um progresso tecnológico incessante, cujas consequências são inegavelmente destrutivas. Assim, o entrelaçamento entre a teoria e a prática apresenta-se inextricável, comprometendo a essência cognoscente da ciência moderna. Várias passagens de Jonas corroboram essas apreciações: "a ciência moderna é essencialmente tecnológica, isto é, a aplicação prática não é acidental, mas sim essencial à teoria científica” (Jonas, 2004, p. 220); “a conexão entre a teoria e a prática tornou-se inextricável" (p. 227); “a teoria passou a ser uma função do uso na mesma medida em que o uso é uma função da teoria” (p. 232).

Ora, a libertação dessa dinâmica fatídica e destrutiva - que é igualmente libertação da valorização compulsiva do poder de intervenção e controle da natureza - exige, para Jonas, uma tomada de distância em relação à tecnociência moderna, quer dizer, exige outra teoria capaz de pôr-se mais além do domínio do uso prático em que se encontra encadeada, de modo a não mais assumir o poder de controle do objeto como seu valor último (cf. Jonas, 2004, p. 230).

Não há dúvida de que o ideal (platônico por excelência) de uma teoria capaz de contemplação das verdades eternas e imutáveis exerce grande fascínio sobre Jonas. Tal ideal apresenta-se para ele como o contraponto necessário ao incessante dinamismo de uma teoria essencialmente destinada à aplicação prática e ao controle do objeto natural que, justamente por isso, torna-se promotora compulsiva de um progresso tecnológico esquecido não só de sua destinação humana, mas de valores próprios da 
natureza (atinentes, por exemplo, à diversidade biológica e à sustentabilidade ambiental). Para pôr freio a esse processo cego faz falta à teoria um ideal transcendente à mera aplicação prática capaz de suscitar a pergunta pelos fins últimos. Ora, essa "outra teoria" capaz de efetivamente "abandonar a caverna", entendamos, capaz de libertarse do processo de tecnologização compulsivo, para então dedicar-se à contemplação, restabelecer sua relação com a verdade e assumir novamente a pergunta pelos fins últimos, essa "outra teoria", dizíamos, atende pelo nome de filosofia (cf. Jonas, 2004, p. 231-2) e, mais exatamente, pelo nome de filosofia platônica, embora não seja como tal denominada por Jonas.

Guardadas as devidas diferenças, a visão joniana da natureza não dominada aparece-nos platônica. Essa natureza intocada, porquanto não apropriada pela tecnociência moderna, é, para Jonas, a verdadeira natureza, cuja contemplação só é facultada ao homem enquanto ser dotado de transcendência. "Só a natureza que é poupada pode revelar-se" (Jonas, 2006, p. 336).

Em conformidade com esse plano argumentativo, que ora exploramos, a adoção de outro conceito de natureza, liberto da concepção antropocêntrica e instrumental prevalecente, apresenta-se como um imperativo ético premente para nossa civilização tecnológica. Não nos parece convincente, contudo, a proposta que Jonas formula com esse propósito, dirigida para "uma nova metafísica do ser no centro da qual conviria meditar sobre o lugar do homem no cosmo e sobre sua relação com a natureza" (Jonas, 2000b, p. 38). E isso porque, no intuito de salvaguardar a verdadeira essência da natureza que se furta ao conceito dela elaborado pela ciência moderna, Jonas julga necessário recorrer à ontologia. Certo é que, como ressalva nosso autor, a natureza não deve ser concebida como essência eterna e imutável, mas sim como existência precária e perecível, isto é, como corpo vivo. Ainda assim, Jonas não deixa de conceder à natureza uma positividade ontológica apreensível tão somente por meio de um conceito transcendente. Ora, permanecerá sempre questionável o quão fidedigna será a visão do "ser da natureza" proporcionada por tal conceito transcendente, assim como permanecerá sempre sob suspeição o grau de isenção de tal conceito.

\subsection{Primeiro motivo grítico}

O motivo crítico que julgamos preciso assinalar nessa vertente argumentativa da obra joniana, aqui abordada, consiste na ausência de referência a uma experiência estética. Ou melhor, na falta de valorização de uma experiência, que poderíamos designar propriamente estética, cujo desiderato seria o de oferecer à natureza (subjugada pelo conceito a ela imposto pela ciência moderna) a possibilidade de configurar-se em constelações imagético-conceituais capazes de tornar manifestos os valores e as finalidades 
que lhe são próprios. Pensamos aqui em uma proposta conceitual nos moldes da elaborada por pensadores frankfurtianos como Adorno e Marcuse (cf. Adorno, 1988; 2009; Marcuse, 1969; 1973; 1999).

Mais precisamente, o desenvolvimento da obra de Jonas ressente-se, a nosso ver, da proposta de uma estratégia conceitual capaz de, mostrando-se sensível à dominação imposta ao objeto natural, dar voz ao sofrimento surdo. Para tanto, tal estratégia deveria mostrar-se capaz de admitir sua própria participação na dominação conceitual que ela acusa e, com isso, contribuir efetivamente para a promoção da reconciliação.

Afinal, do que carecemos não é de um conceito que se eleve sublime aos píncaros de uma transcendência altaneira, a partir da qual uma natureza imaculada viria oferecer-se à contemplação, mas sim de um conceito (ou de uma estratégia de conhecimento) capaz de reconhecer o quanto há de denegação do inferior nesse movimento de afirmação do superior. Com outras palavras, temos necessidade de uma estratégia de conhecimento capaz de reconhecer sua participação na dinâmica de segregação e dominação do natural. Nesta capacidade de reconhecimento da violência exercida pelo espiritual residiria sua verdadeira transcendência.

Justamente porque a natureza nunca é idêntica ao conceito dela elaborado, seria preciso, ao invés de concebê-la como positividade ontológica, percebê-la como figura do negativo que desestrutura a positividade das categorias conceituais de identidade. A natureza que assim se dá a perceber remete a algo difuso capaz de acusar seu recalcamento pelo conceito, vindo a manifestar-se na forma mais elementar de contradição que é a dor. Ela se faz sentir como dor surda ou sofrimento difuso, provocando em nós, quando logra alcançar a expressão, uma espécie de comoção ou estremecimento que é o sinal característico da apreensão estética. Daí a relevância que possui, a nosso ver, o momento mimético para a efetiva superação do pendor dominador de uma concepção instrumental da natureza. É graças à abertura ao outro (não idêntico ao conceito), que nele se perfaz, que uma natureza tolhida pelo conceito e reduzida a mero objeto a nossa disposição tem a oportunidade de alcançar a expressão.

Esse motivo crítico aqui esboçado baseia-se em grande medida no pensamento adorniano. Como se compreende, concedemos à experiência estética um sentido específico, que vai muito além da significação habitual de experiência sensível de fruição da beleza. Por experiência propriamente estética, entendemos a experiência propiciada pela capacidade mimética de reconhecer e produzir semelhanças no contato com a realidade sensível, a qual, facultando a identificação com o outro, é capaz de proporcionar uma forma de conhecimento. Momento essencial e indissociável dessa experiência é o momento em que o sujeito se deixa afetar pelo objeto, cuja alteridade radical e insuspeita o desconcerta, ocasionando um estremecimento característico, conhecido como "calafrio estético". Nesse momento, o sujeito logra abandonar suas catego- 
rias identitárias, liberando-se da estreita visada subjetiva, atinente a seus interesses individuais exclusivistas. É quando o sujeito abre-se ao outro, reconhecendo a legitimidade de interesses alheios e tornando-se capaz de acolher o objeto por seu valor próprio. O objeto, então, se lhe afigura belo, vale dizer, mais que mero objeto. Notemos que uma experiência desse teor, embora propiciada de forma privilegiada pela fruição de uma autêntica obra de arte, pode ter lugar a despeito dela (cf. Adorno, 1988; 2009; Safatle, 2005; Freitas, 2003).

Restituir à natureza a dignidade que lhe é devida, como justamente pretende Jonas, é algo que uma proposta de teor ontológico, tal como a sua, não nos parece ter condições de levar a bom termo. Como poderia, afinal, um pensamento que não concede a devida importância ao âmbito estético e, com ele, ao motivo da expressão da dor e do sofrimento associado à experiência da materialidade sensível, pretender fazer justiça a um ser que é, nas suas próprias palavras, corpo vivo, unidade indissociável de matéria e espírito?

Porque não há, efetivamente, como ser capaz de sensibilizar-se com a ameaça representada pelo poder tecnológico descomunal ao ordo creatio, à totalidade cósmica da criação vista como um organismo vivo, sem antes ter feito a experiência, cognitiva e sensível ao mesmo tempo, do sofrimento imposto a cada criatura individual como violência sentida em si mesmo. A crítica do moderno conceito de natureza não poderia, por isso, prescindir, a nosso ver, de uma reapreciação da componente mimética por parte do logos racional. De outra forma, como poderia um conceito de natureza acolher a singularidade inalienável de cada criatura viva que se encontra subsumida na universalidade do conceito? Como poderia esse conceito voltar-se sobre si mesmo e cobrar consciência da violência exercida na aplicação irrefletida de suas categorias ao corpo vivo? E reconhecer como legítimos outros valores além do valor de controle do objeto natural, eleito como valor supremo pela tecnociência hodierna?

Malgrado o que afirmamos até aqui, é preciso reconhecer que uma leitura atenta da crítica feita por Jonas à proscrição das causas finais na natureza (sob acusação de antropomorfismo), no processo de constituição da ciência moderna, denota certa valorização do caráter mimético do pensamento. Com efeito, nosso autor compreende a condenação da mímesis como um desdobramento da reprovação do animismo, na modernidade, por parte do pensamento científico nascente. A rejeição das causas finais renega, no mesmo movimento, a componente mimética do conhecimento da natureza; desse modo, a natureza passa a apresentar-se como objeto distante e indiferente, passível de análise matemática e mecânica. Em duas palavras, a condenação do animismo redunda na redução da natureza a objeto desvitalizado, com o qual não há identificação possível (cf. Jonas, 2006, p. 4,6-7). 
Para ser consequente, como observa nosso autor, a reprovação de um finalismo antropocêntrico, que toma confusa ou equivocadamente finalidades e propósitos humanos com sendo naturais, deveria contribuir para o reconhecimento de finalidades efetivamente próprias à natureza - e não para, como foi o caso ao longo do processo de consolidação da ciência moderna, terminar por proscrever pura e simplesmente as causas finais da natureza. Tal proscrição termina por reduzir a natureza à matéria sem qualquer propósito ou finalidade, vazia de significação, e assim à completa mercê de controle e agenciamento humano.

O paradoxal dessa dinâmica consiste em que uma justa apreciação da natureza extra-humana como vida dotada de interioridade (em que se manifestam propósitos e intenções) não pode ter lugar sem um mínimo de identificação. É graças à experiência de nossa interioridade (igualmente expressa na forma de impulsos e motivações) que somos capazes de reconhecer uma interioridade semelhante existente fora de nós. Como bem observa Jonas, o reconhecimento da interioridade própria da vida animal "representa uma parte do conhecimento intuitivo da vida pela vida" (Jonas, 2000a, p. 101). Trata-se de um conhecimento intuitivo e imediato (mimético) do mesmo pelo mesmo: "Empédocles tinha razão quando dizia que percebemos o amor pelo amor e o ódio pelo ódio (...). Não reconheceríamos o medo nos outros, se não estivéssemos familiarizados com o medo em nós mesmos" (Jonas, 2000a, p. 102).

O paradoxo acima referido está em que o reconhecimento de uma ipseidade alheia deve ter lugar sob a ingerência das afecções que constituem nossa própria ipseidade. Desse modo, não há espelho cristalino capaz de refletir de modo límpido, isto é, purificado de nossas afecções, a ipseidade alheia. A apreensão pretensamente objetiva falseia seu objeto por carecer de identificação; a apreensão que não proíbe a identificação mimética, em contrapartida, peca por falta de objetividade. Com outras palavras, a apreensão da imagem do outro natural como ser dotado de finalidades próprias, ao requerer a manifestação de nossa interioridade para perfazer-se, não tem como liberar-se inteiramente da projeção antropocêntrica, de sorte que nunca serão inteiramente próprias as finalidades "próprias" que julgamos apreender no outro natural. Tal suspeita termina por solapar a proposta de uma ontologia do ser vivo, por mais crítica do antropocentrismo que se pretenda ser.

Notemos que a questão com que nos debatemos aqui é uma variante da célebre questão relativa à possibilidade de admissão de valores por parte do conhecimento científico, sem que essa admissão resulte na intromissão de valores que venham a comprometer a almejada objetividade do conhecimento.

A propósito ainda do tema da revalorização da componente mimética, é interessante notar que o próprio Jonas compõe deliberadamente um mito (cf. Jonas, 2006, cap. 12, seção 6, p. 264, ss.), cujo propósito é despertar nosso sentimento de responsa- 
bilidade pela totalidade da criação que, hoje mais do que nunca, sofre uma ameaça de destruição por nossa causa. Na medida em que soam desamparadas afirmações metafísicas que procuram reassegurar a transcendência humana, quando esta se encontra mais do que nunca ameaçada, o recurso ao mito procura fazer perceber a transcendência humana não como um dado metafísico inquestionável, mas como resultante de um processo que nos concerne, porque dele tomamos parte, envolvendo toda aventura mortal em si. "Pelo menos desta vez eu me sinto impelido a recorrer ao mito sob a premência de uma tarefa a que a filosofia, em seu desamparo, não pode subtrair-se" (Jonas, 2006, p. 267). Notemos que, ao compor um mito, ele recorre à componente mimético-imaginativa do logos renegada desde Platão, e transpõe o que é próprio do mais próximo (o cuidado que nos inspira um recém-nascido) para o mais distante (a responsabilidade perante a totalidade da criação a ser assumida pelo homem).

Apesar destas últimas observações, é preciso reiterar que a valorização do momento expressivo das configurações imagético-conceituais é, com efeito, um tema praticamente ausente na obra joniana. Mesmo a imagem artística, na sua exposição, não se livra do pendor dominador do eidos (cf. Jonas, 2004, p. 181-205; 2000a, p. 67-70). Também a percepção sensível não se liberta de certo caráter eidético (cf. Jonas, 2004, p. 159 e ss.). Nisso, podemos recriminar, em primeiro lugar, uma dissociação e hierarquização dos sentidos, que denota incompreensão da camada primordial do sentir, em que há verdadeira sinergia entre os sentidos, em segundo lugar, o privilégio concedido à visão que trai a fé perceptiva, própria da ciência moderna, em um olhar distanciado para o qual a realidade (objetiva) é o que se apresenta ao sujeito da percepção como se ele não fizesse parte dela. $\mathrm{O}$ mundo se revela, para esse sujeito cognoscente, como representação de um olhar desencarnado e de sobrevoo (cf. Lories \& Depré, 2003, p. 119-36). ${ }^{2}$

\section{A húbris HODIERNA DA COMPULSÃO TEGNOLÓGIGA}

Contudo, gostaríamos de chamar a atenção para outro plano argumentativo também presente na obra de Jonas. Neste outro plano de argumentação, sobre o qual passamos a deter-nos agora, Jonas não deixa de afirmar, é certo, que a relação que o homem entretém com a natureza, sobretudo desde a modernidade até hoje, seja fundamentalmente uma relação de poder. Talvez não haja tema, aliás, sobre o qual ele mais se estenda, "pois não só a relação do ser humano com a natureza é uma relação de poder,

2 Elaborando um comentário ao estudo "A nobreza da visão" de Jonas, Lories e Depré estabelecem uma comparação com a fenomenologia da percepção de Merleau-Ponty, acusando um "distanciamento pouco radical da visão científica do mundo" por parte de Jonas. 
mas a própria natureza é entendida como um sistema de poder" (Jonas, 2004, p. 216). Sua concisa história do conceito de natureza, lembremos, faz remontar as origens da ciência moderna à noção de uma natureza adversa e mesmo hostil elaborada pelas correntes gnósticas nos primeiros séculos da era cristã. Ainda mais, avalia ele que a humanidade encontra-se hoje dependente desse tipo de relação no mais alto grau; como que obsedada, ela recorre ao exercício de seu poder tecnológico de modo cada vez mais insaciável e frenético.

Jonas continua, pois, reconhecendo a vigência de um conceito de natureza que fundamenta e perpetua o exercício do poder da tecnociência sobre a natureza. No entanto, neste plano de argumentação ele não se atém aos mecanismos teóricos subjacentes de legitimação da dominação, porque a ele preocupa, antes de tudo - dado o caráter emergencial da situação atual - não a proposta de outro conceito de natureza liberto da dominação que ele patrocina, mas a limitação ou o controle do exercício do poder tecnológico. Sua palavra de ordem aqui parece ser que deixemos por ora a ciência moderna como está, esqueçamos aquela investigação em profundidade dos mecanismos de dominação intrínsecos ao seu conceito de natureza, e ocupemo-nos do que é mais premente no momento, isto é, do abuso de sua aplicação prática indiscriminada. Com efeito, o abuso do poder tecnológico é a questão central da ética por ele reclamada para nossa civilização tecnológica. Ao desenvolvimento da ciência não cabe no momento opor entraves nem restrições, mesmo porque o próprio conhecimento científico revela-se necessário, como já observamos, dada sua capacidade de avaliar as consequências, mensurar os efeitos e estimar os riscos socioambientais decorrentes dos mais recentes desenvolvimentos tecnológicos.

Essa última vertente da obra concede, assim, um aval à ciência moderna, endossando seu conceito de natureza, conquanto imponha severas restrições a sua aplicação tecnológica indiscriminada (cf. Jonas, 2006, p. 136 ss.; 2004, cap. 10, p. 211 ss.).

A finalidade é então admitida como um conceito próprio à natureza como um todo. Quanto à causalidade eficiente, ela é entendida como um conceito limitado e parcial, mas, e este é o ponto que nos interessa, compatível com o longo encadeamento teleológico subjacente que lhe escapa. Em flagrante discordância com a imputação de uma natureza intrinsecamente dominadora à racionalidade científica moderna, não há aqui sinal de coerção ou violência conceitual exercida contra o ser natural por parte do sujeito do conhecimento da ciência moderna. E, no entanto, é esse sujeito que, no trabalho de investigação experimental dos processos naturais, determina a causalidade eficiente em cada caso, explorando-a evidentemente em seu proveito, ao estabelecer a partir dela mecanismos de controle.

A reflexão compreensiva, visando à totalidade, ensejada pela filosofia não vem a acusar, nesse plano de argumentação, a mutilação levada a efeito pelo conhecimento 
científico quando este promove uma apropriação seletiva de mecanismos de causalidade eficiente, em detrimento da apreensão de finalidades intrínsecas à materialidade viva e corpórea. Tal reflexão filosófica propõe-se tão somente a complementar o conhecimento científico, evitando reducionismos. Assim, "não se trata de censurar as ciências da natureza, elas devem executar firmemente sua tarefa, mas é preciso que os físicos evitem fazer de sua física uma metafísica, isto é, evitem fazer da realidade que eles conhecem a realidade completa" (Jonas, 2000a, p. 254). O saber da totalidade (metafísico por excelência) fica, portanto, reservado para a filosofia, que não recrimina a visada parcial e seletiva do entendimento científico da natureza (embora esta visada lhe confira seu caráter instrumental), apenas procura impedir que sua visada parcial e limitada seja hipostasiada como visão da realidade no seu todo (cf. Jonas, 2010).

Essa vertente segundo a qual se faz necessário, em caráter emergencial e momentâneo, condenar o progresso tecnológico e simultaneamente absolver o conhecimento científico, na forma pela qual é hodiernamente produzido, termina tornandose hegemônica na obra de Jonas. Em conformidade com ela, a ética para nossa civilização tecnológica caracteriza-se como uma ética de emergência em face da catástrofe planetária iminente, visando, sobretudo, o controle e a moderação do uso desenfreado que fazemos de nosso poderio tecnológico. Caberia então - e este é o papel que, por sua prioridade, assume o primeiro plano na exposição de Jonas - "desenvolver uma sensibilidade às consequências de longo prazo que podem ter a ação humana sobre o delicado equilíbrio existente entre as pretensões humanas e a capacidade de produção da natureza" (Jonas, 200ob, p. 37); sensibilidade que requer, como já assinalamos, o conhecimento proporcionado pelas especialidades científicas, mediante um trabalho de pesquisa interdisciplinar dos processos naturais submetidos à intervenção tecnológica.

\subsection{Segundo motivo crítico}

Ora, a proposta elaborada por Jonas nesse plano de argumentação parece-nos problemática. Poderíamos desde logo formular duas objeções.

(1) Em tempos de triunfo da tecnociência, isto é, de uma total simbiose entre ciência e tecnologia, como conciliar a aprovação incondicional do avanço do conhecimento científico com o interdito imposto à progressão das aplicações tecnológicas? (cf. Jonas, 2006, p. 267). Jonas afirma que a dedicação à ciência é "em si um bem moral”. De que ciência e de que bem moral se trata aqui? Essa ciência não pode ser identificada, evidentemente, com a tecnociência hodierna, assentada sobre a valorização do poder de controle e, por isso mesmo, baseada no emprego de estratégias materialistas descontextualizadoras, que levam à exploração manipuladora da causalidade eficiente em detrimento do reconhecimento de causalidades finais imanentes à 
natureza. Seria uma ciência básica revalorizada em detrimento da ciência aplicada? Não se assemelha ela, antes, a uma ciência imbuída do ideal platônico de contemplação das verdades eternas e do conhecimento desinteressado? A uma ciência que, libertando-se da estreita visada antropocêntrica vigente na caverna da empresa tecnológica, acredita poder contemplar, no céu das ideias, o finalismo intrínseco à natureza como seu verdadeiro ser? Seria nesse sentido que deveríamos entender que a dedicação à ciência, sendo dedicação ao verdadeiro, é, ao mesmo tempo, devoção ao belo e ao bom?

(2) Ao recriminar a húbris da aplicação tecnológica e endossar o livre desenvolvimento da ciência hodierna, Jonas perde a oportunidade de fazer a crítica mais justa à nossa época, qual seja, a crítica da redução da ciência à técnica, consequente à assunção do controle tecnológico como valor último da atividade científica (em conformidade com a argumentação de Hugh Lacey, sobre a qual nos deteremos logo a seguir). Seria preciso não condenar in totum o conceito de natureza instaurado pela racionalidade científica moderna, indigitando uma característica intrinsecamente dominadora a esse conceito de razão dito instrumental (como se dá grosso modo nas visões fáusticas da ciência, entre as quais podemos incluir o pensamento dos integrantes da Escola de Frankfurt formulado a partir da década de 1950), nem isentar inteiramente tal conceito, fazendo recair toda responsabilidade sobre o processo irrefreável do progresso tecnológico. O mais acertado seria, ao que nos parece, acusar criticamente um momento particular e, por isso mesmo, superável, dessa figura da razão, segundo o qual a ciência vê-se reduzida à pesquisa empírica sistemática norteada pelo valor exacerbado do controle e da manipulação tecnológica. Com essa redução, a riqueza e a diversidade da observação resultante da livre pesquisa experimental, constitutiva da ciência moderna em suas origens, restringe-se à manipulação e à apropriação seletiva de dados experimentais exclusivamente voltados para o controle tecnológico desejado, seu valor último. Desse modo, o valor intrínseco do conhecimento (que diz respeito ao conhecimento desinteressado do objeto como fim em si mesmo, que demanda o acolhimento de múltiplas perspectivas de valor) subordina-se, como nunca dantes, ao valor instrumental de manipulação tecnológica desse objeto. Consequentemente, as causas finais pressupostas na estrutura subjacente da matéria viva (que requerem a mobilização de diversos níveis de interpretação para que sejam plenamente compreendidos, assim como a elaboração de constelações imagético-conceituais capazes de apreender seu momento expressivo) reduzem-se, em uma circularidade determinista, aos mecanismos causais eficientes mobilizados no contexto da aplicação tecnológica (cf. Leite, 2006).

Em outras palavras, o segundo motivo crítico poderia ser assim resumido. Ao acusar o sortilégio que pesa sobre a civilização hodierna, que ele próprio designa como sendo o "círculo de encantamento mágico da vocação tecnológica” (Jonas, 2006, p. 43), 
Jonas reconhece a necessidade premente de conquistar um poder sobre o poder, superando a "impotência em relação à compulsão do poder que se nutre de si mesmo na medida de seu exercício" (2006, p. 237). Contudo, se procuramos responder com ele a pergunta, "de onde se pode esperar este poder de terceiro grau que restituirá ao homem novamente - e ainda a tempo - o controle sobre seu poder, quebrando o sortilégio desse poder autônomo, que se tornou tirânico?" (2006, p. 237), seremos obrigados a concluir que sua perspectiva de emancipação está respaldada, fundamentalmente, na crítica da utopia tecnológica, isto é, em um processo de esclarecimento capaz de desbaratar a ideologia legitimadora do progresso tecnológico desenfreado e encobridora de suas catastróficas consequências. Esse processo de esclarecimento, infelizmente, como ele mesmo afirma, talvez só possa ser desencadeado efetivamente depois que algumas dessas catastróficas consequências tenham lugar, apostando, evidentemente, que a humanidade não venha a perecer de uma vez por todas com essas catástrofes.

Seja como for, a crítica da ideologia legitimadora do progresso tecnocientífico, que sua obra julga preciso empreender, busca, em última instância, debelar o processo compulsivo das aplicações tecnológicas, considerado perverso em si mesmo, não se permitindo considerar de que outra forma o progresso tecnocientífico poderia vir a desenvolver-se para tornar-se efetivamente capaz de atender a valores humanos, sociais e ambientais. Este é, mais exatamente, o ponto que julgamos ser preciso recriminar nessa proposta de Jonas.

\section{Para alÉm da primazia do valor de Gontrole}

Uma das propostas atuais mais promissoras para superar os impasses aqui assinalados a que conduz a proposta joniana é, a nosso ver, o modelo desenvolvido por Hugh Lacey de interação entre a ciência e os valores. Embora esse modelo já tenha sido bastante divulgado e comentado entre nós, gostaríamos de tornar a apresentá-lo aqui com o propósito de sugerir uma interpretação particular, cujo teor ficará claro no decurso da exposição. Como iremos delineá-lo em largos traços, escusamo-nos antecipadamente pelas simplificações grosseiras que serão cometidas (cf. Lacey, 2008, cap. 6; 2010, cap. 3, 11).

Afirma Lacey que, nas instituições científicas hodiernas, prevalece a ideia de que a ciência tem como objetivo último gerar inovações tecnocientíficas que contribuam para o crescimento econômico e, de modo geral, para o progresso tecnológico e econômico. Por esse motivo, essas instituições priorizam a adoção de estratégias de pesquisa materialistas descontextualizadoras, que mantém relações de reforço mútuo com os valores do progresso tecnológico, do capital e do mercado. Tais estratégias procu- 
ram representar as leis e as estruturas dos fenômenos dissociados do contexto social, humano e ecológico em que se encontram inseridos, valorizando sobremaneira o controle tecnológico alcançado. Por conseguinte, fatores ambientais, valores humanos e sociais tendem a ser desconsiderados. A preponderância quase exclusiva de estratégias materialistas descontextualizadoras, visando o controle tecnológico, não deixa de fornecer conhecimento objetivo válido, mas fere o princípio da neutralidade científica, posto que a atividade tecnocientífica passa a subordinar-se prioritariamente a interesses econômicos, promovendo o que se costuma chamar de processo de "mercantilização da ciência" ou, na terminologia de Lacey, "tecnologia comercialmente orientada".

À estratégia materialista atualmente prevalecente na atividade científico-tecnológica, que apresenta uma afinidade eletiva com o valor de controle baconiano, Lacey propõe uma abordagem alternativa. Uma abordagem que - sem por isso mesmo deixar de ser científica - colocasse em segundo plano o valor da intervenção com fins de controle em favor de outros valores, notadamente dos valores da sustentabilidade ambiental, da emancipação social e do florescimento humano em geral. Tal abordagem alternativa deveria possuir como objetivo, nas palavras de Lacey,

sintetizar confiavelmente (em teorias racionalmente aceitáveis, ou em corpos de conhecimento sistematicamente organizados) as possibilidades acessíveis à interação humana com um domínio de objetos que pudessem servir para intensificar a manifestação dos valores de estabilidade social e ecológica e para descobrir meios de realização de algumas possibilidades até então não realizadas (Lacey, 1998, p. 83).

O desiderato maior dessa reestruturação da atividade científica seria, assim, torná-la capaz de contemplar efetivamente valores (morais, sociais e ambientais) relativos ao bem-estar humano e à preservação da diversidade natural.

A questão que gostaríamos de formular aqui é então se tal proposta de uma abordagem alternativa capaz de retirar a primazia concedida ao valor de controle na atividade científica hodierna incorpora um momento mimético graças ao qual ela (essa abordagem) seria capaz de fazer-se sensível ao sofrimento imperante, vale dizer, à miséria e à opressão social, à exploração e à degradação da natureza. A que atribuir então esse momento sensível à dominação e à opressão vigentes? Dominação, ademais, reiterada pela própria atividade científica porquanto adota uma abordagem (como é o caso da estratégia materialista) que assume tacitamente o valor de controle como último e universal? 
A fasginaÇÃo da Gompulsão tegnológiga...

Uma abordagem capaz de contemplar o florescimento humano e a preservação da exuberância natural precisaria libertar-se, é certo, da valorização inconteste do poder de controle dos processos naturais, mas também, no mesmo movimento, tornarse sensível à miséria social e à degradação do meio ambiente natural; o que também quer dizer tornar-se sensível ao florescimento humano que não se realiza com o progresso da ciência nos moldes atuais (cf. Lacey, 1998, p. 176-7). Mais ainda, talvez fosse preciso considerar que a desejada superação da valorização extremada do poder de controle tenha como condição prévia o desenvolvimento de uma nova forma de sensibilidade - e de capacidade de identificação com o objeto do conhecimento - que não é aquela promovida pelas estratégias materialistas descontextualizadas que nortearam o desenvolvimento da ciência moderna.

O que gostaríamos de sugerir aqui é a relevância da participação ou mesmo da intervenção de uma dimensão estética para a transformação da estratégia materialista prevalecente (fortemente associada à valorização moderna do controle) em estratégias diversas sensíveis à promoção do bem-estar humano. Em outras palavras, gostaríamos de chamar a atenção para a importância da componente mimética (com a capacidade de abertura ao outro que ela encerra) como elemento-chave no abandono (ainda que relativo) de uma estratégia obcecada pelo controle do objeto natural em prol de estratégias diversas capazes de acolher o objeto por seu valor próprio (ver a nota 2).

A proposta formulada por Lacey para a reestruturação da atividade científica centra-se, fundamentalmente, na reapreciação da dimensão dos valores sociais por parte da prática científica. Considerações relativas à reapreciação da dimensão estética não tomam parte dela, ao menos não expressamente, até onde é de nosso conhecimento. Apesar disso, não são poucas as ocasiões em que a pressupõe ou deixa-a subentendida. Assim, por exemplo, quando afirma que a legitimação de outras estratégias científicas capazes de resolver o problema da fome no mundo (malgrado já se produzam, graças às conquistas da tecnociência hodierna, alimentos em quantidade suficiente para que todos sejam alimentados) requer um esquema teórico que "focalize o nexo causal completo da produção e consumo de alimentos e, mais geralmente, do bemestar humano, em um processo sensível às necessidades, interesses e perspectivas de valor de todos" (Lacey, 2010, p. 94-5). Ora, ao que nos parece, a efetivação desse processo "sensível às necessidades, interesses e perspectivas de valor de todos", pressupõe uma capacidade de identificação com o outro que é o apanágio de uma experiência propriamente estética.

Não seria mesmo possível entender o processo de incorporação da componente mimética pela racionalidade tecnocientífica, na qual aqui insistimos, como um processo solidário à admissão de um pluralismo metodológico capaz de romper a hege- 
monia prevalecente da abordagem descontextualizada, na terminologia de Lacey? Com efeito, não seria um apanágio da dimensão estética essa representação dos fenômenos, sensível ao lugar que possuem em relação aos arranjos sociais, às vidas, experiências e atividades humanas, aos valores e qualidades sensoriais? Pois são justamente esses os aspectos que devem ser contemplados, segundo Lacey, por uma abordagem que não mais descontextualiza os fenômenos, vale dizer, não mais os dissocia de toda possibilidade que apresentem em virtude de sua inserção em contextos sociais, humanos e ecológicos particulares (cf. Lacey, 2008, p. 3०5).

Ainda nesse sentido, é interessante observar o que Lacey propõe para abalar a convicção cega de que não há possibilidade de satisfação das carências e necessidades humanas fora das estruturas neoliberais, entendamos, fora das estruturas impregnadas pelo valor de controle legitimador da ciência moderna, caracterizadas por individualismo, competitividade, riqueza material e crescimento econômico. Ora, o que Lacey propõe é atentar para os grupos marginalizados pelas estruturas neoliberais predominantes (grupos que não tiveram e jamais terão suas reais necessidades atendidas por essas estruturas) e também para as práticas alternativas por eles desenvolvidas. "Estou me referindo especialmente a grupos de pessoas empobrecidas que vivenciam grandes sofrimentos que possuem em grande medida causas estruturais" (Lacey, 1998, p. 205). São pessoas para as quais a crença no progresso da ciência e da tecnologia no interior de estruturas neoliberais não traz esperança de uma vida em que suas carências serão eliminadas e suas necessidades atendidas.

Assim, para Lacey, a fonte de novas possibilidades brota das margens. Mister é atentar para elas e conceder a devida relevância a movimentos locais de grupos marginalizados pelo processo global. Uma real modificação das estruturas dominantes não deve ser esperada na forma de um processo global arquitetado a partir de cima, mas sim a partir de movimentos periféricos gestados a partir de baixo, os quais, pela progressiva imposição de valores locais, viriam a minar gradativamente as estruturas de dominação global (cf. Lacey, 1998, p. 206). É preciso, assim, fazer com que a atividade científica venha a contemplar as necessidades insatisfeitas dos marginalizados pelo processo global, buscando atender, com sua atividade de pesquisa e desenvolvimento tecnológico, as carências particulares e locais, colaborando construtivamente com a crescente insatisfação que brota das margens em consequência de carências não atendidas - por que não dizer? - pelo desenvolvimento científico-tecnológico norteado fundamentalmente pelo valor de controle.

Mas o que poderia levar a atividade científica a se mostrar sensível a valores outros que não o valor de controle baconiano, prevalecente até então de forma inconteste? De que necessitaria ela para passar a atuar como poder de emancipação social e de pre- 
servação da diversidade natural, ao invés de continuar a contribuir, em uma circularidade viciosa, com o desenvolvimento da dinâmica neoliberal, participando cegamente do processo de tecnologização e mercantilização geral?

Lacey considera que cabe em parte às ciências sociais a resposta à pergunta de "como a ciência deve ser conduzida para promover o bem-estar humano". Ele propõe fomentar o estabelecimento de relações recíprocas entre as ciências naturais e sociais, depositando nas mãos das ciências sociais a investigação capaz de identificar, em cada contexto social específico, as perspectivas de valor carentes de serem contempladas. A partir dessa identificação, um conjunto de estratégias poderia ser explorado pela atividade científica. Em última instância, porém, a deliberação a favor de investigações sociais realizadas com esse propósito caberia à livre atuação das forças sociais manifestas em um processo plenamente democrático. Perspectivas de valor diversas, adequadamente diagnosticadas pela investigação social, poderiam assim vir a informar a prática científica de modo a promover o bem-estar humano em cada contexto específico (cf. Lacey, 2010, cap. 3, p. 120-4). Destarte, se entendemos bem, a proposta de Lacey considera que o primo movens de tal transformação devem ser forças externas à atividade científica, que precisariam passar a atuar mais decisivamente no sentido de orientá-la ou supervisioná-la, quer essas forças atuem diretamente, por deliberação democrática, quer indiretamente, mediante investigação social. Ou, ao contrário, essa acalentada reciprocidade entre as ciências naturais e sociais enseja uma reformulação do paradigma científico a partir de dentro? Como entender exatamente a consecução dessa proposta destinada a fazer com que a atividade científica venha a ser informada pelas distintas perspectivas de valor?

A dificuldade em responder a essa questão está, até onde podemos ver, em não se conseguir discernir com clareza se a mudança deve ser concebida:

(1) como uma reorientação da atividade científica decorrente da atuação diretiva e planificadora de agente externo - preferencialmente forças sociais democráticas -, exercida no sentido de exigir que a autonomia conquistada pela atividade tecnocientífica seja permanentemente submetida ao debate público e nele se justifique. Desse modo, seria constantemente exigido da atividade científica o atendimento de valores a princípio extrínsecos a sua prática, posto que renegados por sua estratégia descontextualizadora, mas essenciais à vida em geral, tais como a liberdade e a dignidade pessoais, justiça social e sustentabilidade ambiental. $\mathrm{O}$ que as forças sociais exigiriam da atividade científica seria a adoção de estratégias diversas da estratégia materialista promotora do valor de controle, estratégias essas capazes de satisfazer outras perspectivas de valor e assegurar uma genuína neutralidade aplicada, em conformidade com a proposta formulada por Lacey em diversas ocasiões (cf. Lacey, 2008, cap. 6; 2010, cap. 3, 11); 
(2) ou como transformação advinda do interior, resultante de uma reformulação do próprio paradigma epistemológico vigente calcado na noção de neutralidade axiológica e no valor prevalente do controle tecnológico da natureza. Tal reformulação promoveria uma teoria que, incorporando um momento que poderíamos designar como mimético, seria capaz de oferecer a seu objeto a oportunidade de expressar-se em constelações imagético-conceituais; destarte, tal teoria lograria reconhecê-lo por seu valor intrínseco, e não em função do valor de controle propiciado pelo conhecimento desse objeto. Essa acalentada reorientação do paradigma epistemológico vigente poderia realizar-se mediante o exercício de um efetivo pluralismo metodológico, no qual as múltiplas estratégias de pesquisa encontrariam a possibilidade de desenvolverem-se livremente, desde que motivadas por um momento, que aqui denominamos mimético, sensível à natureza do objeto (e por isso capaz de reconhecê-lo por seu valor próprio) e igualmente sensível às diversas perspectivas de valor manifestas no debate democrático;

(3) ou ainda, como ambas as coisas ao mesmo tempo, interagindo e alimentando-se reciprocamente ao longo de um processo de transformação em que as dimensões socioeconômicas não se separam de dimensões metodológicas e epistemológicas, nas quais consideramos relevante atentar para a reincorporação do momento mimético expurgado ao longo do processo de esclarecimento.

É bem possível que o processo de configuração de uma nova constelação epistemológica, emancipada da dependência obsessiva do valor de controle, seja solidário ao processo de consolidação de uma nova constelação social liberta dos valores de crescimento econômico, progresso material e competição individual hoje prevalecentes. Nova constelação social esta enfim sensível aos valores da solidariedade, da justiça social e da harmonia com o meio ambiente, em que a reconciliação - e não o controle do que vive em estado de permanente dissensão - assumiria o papel de valor predominante. Uma reconciliação entendida não em termos da conquista do repouso ou da inação, mas em termos do predomínio da compreensão e da colaboração mútua nas formas de relação que o homem entretém com seus semelhantes e com a natureza.

Com efeito, uma apreciação do modelo de interação entre a ciência e os valores, realizada a partir de trabalhos mais recentes de Hugh Lacey, deixa claro que sua proposta contempla efetivamente uma interação recíproca entre fatores intrínsecos e extrínsecos à atividade científica. De acordo com essas últimas formulações, podemos conceber que a atividade científica desenvolve-se em cinco etapas (ou momentos), a saber, (1) adoção da estratégia de pesquisa; (2) empreendimento da pesquisa; (3) avaliação cognitiva das teorias e hipóteses; (4) divulgação dos resultados científicos; (5) aplicação do conhecimento científico. Segundo Lacey, os valores epistêmicos, relativos à adequação empírica, à consistência e ao poder explicativo das teorias e hipóteses, 
desempenham um papel determinante na terceira etapa; também nas demais etapas, tais valores cognitivos podem desempenhar papéis próprios, em interação com outros tipos de valores, mas, na terceira etapa, somente valores cognitivos desempenham um papel legítimo. Os valores sociais (neles englobando os valores éticos, políticos, ideológicos e econômicos) podem desempenhar papéis em todos os outros momentos, com exceção do terceiro. Desse modo, a influência de valores sociais é admitida sem que essa influência coloque em questão a objetividade e a imparcialidade do conhecimento, assegurados na terceira etapa. As críticas de teor social, ético, econômico e mesmo ideológico podem ser realizadas relativamente às estratégias de pesquisa adotadas, ou relativamente às aplicações do conhecimento obtido, sem com isso contestar ou invalidar a imparcialidade (objetividade) do conhecimento adquirido. Um dos méritos do modelo reside justamente no fato de sustentar a distinção entre os valores cognitivos/epistêmicos e os valores ético/sociais de modo a assegurar o caráter imparcial e objetivo do conhecimento, ao mesmo tempo em que considera admissível e mesmo desejável a influência de valores sociais na atividade científica. Pode-se afirmar, por isso, que Lacey recusa o preceito positivista da "ciência isenta de valores", que impõe a dissociação entre fato e valor (ou entre o âmbito do descritivo e do prescritivo), mas não a ponto de assentir com o relativismo pós-moderno, que considera a objetividade do conhecimento científico defraudada pela ingerência de valores sociais, interesses econômicos ou ideológicos extrínsecos à atividade científica.

A conquista de uma efetiva neutralidade só se faria possível, segundo o modelo exposto, na medida em que as instituições científicas passassem a admitir uma multiplicidade de estratégias de pesquisas, sensíveis a toda uma gama de valores manifestos em uma sociedade democrática. Por um lado, isso exige uma reformulação do paradigma epistemológico vigente a partir de dentro, isto é, uma transformação intrínseca ao modus operandi da atividade tecnocientífica (para essa transformação, chamamos a atenção para a relevância do momento mimético). Por outro lado, a promoção de múltiplas estratégias demanda, no mesmo movimento, uma crescente participação social, como fator extrínseco à atividade científica estritamente concebida. Para tanto, os movimentos sociais devem tornar-se cada vez mais capazes de reivindicar, no seio de uma sociedade democrática, o atendimento, por parte da atividade tecnocientífica, de valores que lhe sejam essenciais, como, por exemplo, o respeito à dignidade humana, a justiça social, a segurança alimentar, o controle e prevenção de riscos à saúde, a sustentabilidade ambiental e a preservação da diversidade natural.

O processo de interação entre a ciência e os valores deve consubstanciar-se, assim, na forma de uma interação crescente entre as instituições científicas e as comunidades sociais, requerendo, entre outras coisas, abertura dos cientistas para o reconhecimento das demandas, necessidades e problemas socioambientais; o esclare- 
cimento dos cidadãos relativamente às potencialidades e aos riscos dos desenvolvimentos tecnológicos planejados; a participação efetiva das comunidades, devidamente esclarecidas, em processos decisórios responsáveis pela orientação das atividades científicas e tecnológicas a serem empreendidas. Também se faz necessária a promoção de uma efetiva autonomia da ciência, buscando a independência do poder econômico, assim como o estímulo ao princípio de precaução em relação à aplicação imediata de inovações tecnológicas (cf. Lacey, 2008). Desse modo, as deliberações relativas ao desenvolvimento e ao emprego de inovações científico-tecnológicas passariam a ser tomadas no âmbito de uma verdadeira política democrática (com participação conjunta de cidadãos cientistas e não cientistas), deixando de resultar de decisões independentes dos institutos de pesquisa, seja com o fomento do Estado, seja com o patrocínio de empresas cujo objetivo primeiro é, obviamente, gerar lucro.

\section{Conclusão}

Para concluir, gostaríamos de esboçar dois breves comentários com o propósito de explicitar em que sentido a participação do momento mimético, que aqui advogamos, pode contribuir para a almejada emancipação da compulsão pelo controle predominante na atividade tecnocientífica hodierna, em conformidade com o modelo de reestruturação da atividade científica defendido por Hugh Lacey.

Marcos Barbosa de Oliveira (2008), após apresentar o tema central de seu artigo - o preceito da neutralidade axiológica instituído pela ciência moderna -, passa a tratar da problemática crucial de nossa época, qual seja, a dinâmica avassaladora, insustentável e até mesmo destrutiva assumida, hodiernamente, pelo progresso tecnocientífico baseado nas práticas de controle da natureza e valorizado, essencialmente, por promover o crescimento econômico. Daí o desiderato, apresentado no artigo em questão, de explorar a noção de autocontrole (entendida em termos de obtenção do controle da compulsão pelo controle) como alternativa às práticas de controle e dominação da natureza em três âmbitos distintos, a saber, o individual, o das formas de organização social e o das práticas científicas. É certo que esses três âmbitos encontram-se estreitamente inter-relacionados, como reconhece o próprio autor. Contudo, se nos for permitido aventar uma interpretação da exposição empregada por Oliveira, ousaríamos afirmar que ela, partindo do plano individual, avança em direção ao nível social e do social dirige-se ao âmbito das práticas científicas em busca do elemento chave, isto é, daquele elemento que poderia fornecer o ponto de apoio mais consistente para o processo de transformação almejado. 
Partindo do nível individual, Oliveira entende a prática do autocontrole como uma imposição consciente e voluntária de um menor padrão de consumo por parte de cada um de nós, o que poderia inibir o apelo por maior crescimento econômico e promover uma economia mais sustentável. Taxas mais baixas de produção implicam, evidentemente, menor exploração predatória da natureza, taxas mais baixas de poluição etc. (Oliveira, 2008, p. 103). No entanto, isso exigiria uma mudança de mentalidade difícil de ser alcançada no contexto das sociedades capitalistas, tão impregnadas de valores competitivos e consumistas. Mais do que de difícil execução, a proposta de um autocontrole individual parece-lhe até mesmo inviável no seio do sistema capitalista, cujo âmago vital é a lógica inexorável de acumulação do capital por meio do crescimento econômico. Essa constatação conduz à necessidade de conceber-se uma nova forma de organização social em que a regulação das atividades econômicas não mais se encontrasse relegada ao mercado (como se dá no sistema capitalista e, de forma acentuada, no neoliberalismo), implicando na verdade em falta de regulação econômica (cf. Oliveira, 2008, p. 106).

A proposta de autocontrole no plano social é entendida por Oliveira em termos da desejável regulação das atividades econômicas, de acordo com a qual a sociedade como um todo passaria a assumir a própria gestão de sua vida econômica, seu autocontrole, tal como almejado pelos sistemas socialistas, visando à contemplação de valores mais fundamentais, como equidade e justiça social. No entanto, o fracasso da experiência comunista no Leste, na qual o planejamento da vida econômica prosseguiu norteado pelo desenvolvimento incessante das forças produtivas, vale dizer, pela valorização inconteste do progresso científico e da expansão do controle tecnológico como propulsores do crescimento econômico, leva à constatação de que a superação do sistema capitalista, embora necessária, não é suficiente por si só. A condição mais fundamental, ainda não alcançada, consistiria na adoção, por parte dos agentes sociais que devem assumir a autogestão das atividades econômicas, de outros valores mais fundamentais que o crescimento incessante baseado no progresso tecnológico. Isso conduz a investigação do autocontrole almejado do plano social para o âmbito das práticas científicas (cf. Oliveira, 2008, p. 108-9).

Nesse âmbito, estão em questão as práticas de controle e dominação da natureza em que se funda o progresso tecnocientífico desde a modernidade e que impulsionam o crescimento econômico, medido em termos do aumento dos níveis de produção e consumo. A noção de autocontrole é, nesse plano, advogada por Oliveira como alternativa ao valor de controle prevalecente na ciência moderna especialmente no último século, período em que o valor de controle se viu sobrevalorizado em consonância com os processos de tecnologização e mercantilização da ciência, tal como ele os descreve (cf. Oliveira, 2008, p. 112-3). 
Para bem compreender sua argumentação, devemos aqui ter em mente uma das teses principais defendidas por Oliveira, referente à relação entre a neutralidade axiológica e a autonomia da ciência. Segundo essa tese, em um primeiro momento, a reivindicação de neutralidade axiológica atuou de forma decisiva em favor da conquista de autonomia da ciência nascente, notadamente frente à tutela religiosa. Em nossa época, no entanto, a insistência em uma atividade livre de valores (sociais, morais, estéticos, ambientais) reverte-se em seu contrário, isto é, na heteronomia da ciência frente aos poderes do mercado, porque, ao não admitir a ingerência de outros valores além do valor instrumental de controle, a atividade científica termina por sucumbir a um duplo processo que compromete sua autonomia: concede-se importância extrema ao conhecimento que demonstra ter utilidade e aplicação imediatas (que redunda na tecnologização da ciência) e a atividade tecnocientífica passa a ser orientada em função de sua rentabilidade (que resulta na mercantilização da ciência). (cf. Oliveira, 2008, p. 112)

Eis porque a conquista de uma verdadeira autonomia só poderia ser obtida graças ao acolhimento, por parte da atividade científica, de outros valores além do valor concedido, de forma tácita e praticamente exclusiva, ao controle tecnológico em nossos dias. Somente recusando o preceito da neutralidade axiológica e acolhendo de forma declarada valores morais, sociais e ambientais em sua prática, a ciência lograria superar o processo de tecnologização e mercantilização a que sucumbe e que a impede de atuar efetivamente como força progressista em prol da justiça social, da sustentabilidade ambiental e do respeito à diversidade natural. Como se compreende, essa proposta guarda grande afinidade com a abordagem formulada por Lacey a que nos referimos há pouco.

Em resumo, a conquista do autocontrole no âmbito das práticas científicas requer que essas práticas submetam-se a questionamentos em termos de valor; o que, por sua vez, exige que tais práticas venham a abandonar a prepotência costumeira de arrogar a ciência como única forma de conhecimento legítima e, a partir de um exercício de autocrítica, abram-se ao diálogo com outras formas de conhecimento, inclusive as tradicionais. Essa desejável transformação nas práticas científicas dominantes concernem não só as instituições científicas no seu todo, é certo, mas também cada cientista em particular envolvido com pesquisas científicas e desenvolvimentos tecnológicos.

Ora, do ponto de vista da economia psíquica dos agentes individuais mais diretamente envolvidos com as atividades tecnocientíficas, gostaríamos de sugerir que seria interessante procurar contemplar o desiderato de conquista do autocontrole, formulado por Oliveira (2008), em termos um pouco diversos, embora complementares, a saber, em termos da superação do processo de racionalização consolidado ao longo da modernidade e caracterizado, fundamentalmente, pela conquista da fria objetivi- 
dade calculista própria do sujeito do conhecimento da ciência moderna. Esse processo exigiu e ainda exige, em grande medida, controle e recalcamento de impulsos, afetos e paixões em prol da requerida impassibilidade emotiva (precondição para a implementação do preceito da neutralidade axiológica). Nesse sentido, não devemos desconsiderar - e este é o aspecto para o qual gostaríamos de chamar a atenção - que o impulso pelo controle da natureza externa, prevalecente na empresa tecnocientífica hodierna, mostre-se compulsivo na medida em que consista na contrapartida do processo de dominação imposto à natureza interna do sujeito do conhecimento (consumada mediante subjugação do momento mimético). Desse modo, poderíamos entender a proposta da conquista de um autocontrole (ou de superação da inclinação compulsiva pelo controle), por parte do sujeito envolvido com atividades tecnocientíficas, em termos da superação de sua fria impassibilidade, graças à qual esse sujeito venha a tornar-se capaz de identificar-se com o outro, acolhendo valores diversos daqueles estabelecidos por sua estreita visada subjetiva, defensiva ou manipuladora; em outras palavras, venha a tornar-se capaz de acolher o objeto do conhecimento por seu valor próprio, e não meramente em vista do controle tecnológico capaz de ser auferido sobre ele.

Por esse motivo, julgamos oportuno procurar complementar a descrição desse acalentado processo de desenvolvimento do autocontrole, delineado por Oliveira, cuja meta é a emancipação da ciência em um sentido amplo (com a correspondente reconquista de sua autonomia efetiva e recuperação de sua dignidade), fazendo referência à desejável participação da experiência estética, que deve implicar a valorização da ingerência do impulso mimético. Tal complementação deve poder enriquecer e aprofundar sua argumentação, mostrando que, no plano das práticas científicas, o autocontrole almejado reveste-se de um sentido paradoxal, pois só é capaz de consumar-se mediante a passagem por uma espécie de perda de controle do sujeito do conhecimento, que se dá no momento em que o impulso mimético não recalcado, que faculta a identificação com o outro, encontra a ocasião de manifestar-se. Parece-nos aconselhável, por isso, salientar o quanto essa noção de autocontrole, quando adequadamente compreendida, encontra-se imbuída de um impulso de abertura e acolhimento do outro (mimético por excelência), graças ao qual pode parecer legítima a reivindicação de um valor alheio, a exigir respeito, reciprocidade e compreensão, para além da estrita observância da neutralidade axiológica, muito embora tal impulso não se encontre explicitado na exposição de Oliveira.

Em resumo, a conquista de uma autêntica autonomia, capaz de suplantar a fria impassibilidade do sujeito racional e sua compulsão pelo controle, requer assim, e de modo paradoxal, o abandono da pulsão impositiva do autocontrole, propiciado pela livre manifestação de um impulso, mimético por excelência, que promove a identificação com o outro e o acolhimento de valores alheios ao estrito interesse individual. 
Por fim, parece-nos interessante recorrer, ainda que muito brevemente, aos estudos de Andrew Feenberg no intuito de procurar compreender a ênfase que aqui propomos na reabilitação da componente mimética, que se orienta para uma reformulação do paradigma epistemológico a partir de dentro, fundamentalmente como promotora de acolhimento de múltiplas perspectivas de valor. A esse respeito, Feenberg (2004) mostra-se valioso, na exata medida em que sua interpretação da proposta marcusiana de "sensibilização" da racionalidade tecnológica, cuja proposta é de reformulação da própria racionalidade tecnológica, e não meramente da práxis tecnológica, nela descobre uma dimensão política (cf. Feenberg, 1991, p. 100). ${ }^{3}$

Essa interpretação desenvolve os insights marcusianos concernentes a uma tecnologia "afirmativa da vida" no sentido da construção de uma racionalidade tecnológica plena, redesenhada pela "imaginação produtiva", entendida como a promoção de um conceito alternativo de razão capaz de contemplar as dimensões éticas e estéticas que foram dissociadas da dimensão epistêmica no desenvolvimento do paradigma científico moderno. Desse modo, essa nova concepção de racionalidade tecnológica mostrar-se-ia capaz de acolher os valores sociais e ambientais, uma vez que é sensível à manifestação dos mais diversos atores sociais de uma sociedade democrática. Para Feenberg,

\begin{abstract}
Marcuse argumenta que os valores afirmativos da vida são realmente intrínsecos à tecnologia e não uma mera imposição (...). Mediações éticas e estéticas desempenham um papel fundamental nesse processo, integrando princípios técnicos com uma concepção de racionalidade condizente com os valores sociais e naturais (Feenberg, 1991, p. 105).
\end{abstract}

O sistema capitalista, ou o estágio atual do sistema capitalista, com o interesse restrito por competitividade, proveito e lucro que lhe é próprio, neutraliza tais mediações estéticas, tornando a tecnologia insensível a outros valores (sociais e naturais), para além do valor de controle. Assim, uma racionalidade que, em seu sentido pleno, seria capaz de orientar-se por valores sociais e ambientais, cai vítima de uma espécie de mutilação imposta pelo banimento de componentes estético-éticas, que faz com que assuma um caráter eminentemente instrumental, voltado exclusivamente para o controle (cf. Feenberg, 1991, p. 108).

3 Recomendamos ainda vivamente ao leitor o estudo sobre o pensamento marcusiano de Pisani (20o9), que interpreta a recusa da tese da neutralidade da ciência e a defesa de uma nova ciência dotada de uma forma de razão sensível (posto que liberada da forma de razão reinante, repressiva e instrumental) na perspectiva da proposta de reconstituição dos laços entre a ciência e a política. 
A fasginação da Gom pulsão tegnológiga...

Em suma, a proposta de incorporação de componentes ético-estéticas, por parte da racionalidade tecnológica prevalecente, deve ser entendida como solidária a um processo pelo qual a atividade tecnocientífica passaria a acolher valores manifestos pelos mais diversos atores sociais no exercício de uma democracia plena, valores relativos, por exemplo, à justiça social, à sustentabilidade ambiental e à dignidade humana. Por conseguinte, esse processo articula-se com uma concepção de democracia substantiva. "Sugiro que a noção marcusiana de um critério estético para o novo logos técnico seja interpretada como uma tentativa de articular uma concepção de democracia substantiva, orientada para o futuro" (Feenberg, 1991, p. 109).

Ainda que essa interpretação do pensamento marcusiano, aqui apenas referida, careça de um desenvolvimento mais elaborado e aprofundado, ela já é suficiente para permitir vislumbrar o quanto a argumentação em prol de mediações estéticas, desde que devidamente entendida, mostra-se condizente com o modelo de reestruturação das atividades científicas defendido por Hugh Lacey. Além disso, ao que nos parece, essa argumentação é capaz de iluminar o modelo da interação de modo singular, revelando uma nova dimensão antes mal percebida, mas nem por isso menos atuante ou de somenos importância.

Por outro lado, não há como negar que o modelo da interação de Lacey lança uma luz esclarecedora sobre as propostas de reencantamento da ciência dos mais diversos matizes, entre as quais podemos incluir tanto a marcusiana como a adorniana. Tais propostas frequentemente permanecem no plano conceitual mais abstrato de crítica ao conceito de racionalidade científica vigente (quando não de recriminação da tecnociência, como se dá com Jonas), não se permitindo conceber como a atividade científica poderia vir a ser reconfigurada de modo a tornar-se efetivamente sensível a valores fundamentais. O resultado costuma ser o de colocar sob suspeição a ciência estabelecida- a ciência e a técnica são identificadas com a dominação -, esperando o advento de uma nova ciência no bojo de um processo revolucionário ou emancipatório mais amplo, de caráter socioeconômico. Ora, o modelo da interação de Lacey escapa dessa armadilha, na medida em que se propõe investigar a partir de dentro as necessárias transformações do paradigma tecnocientífico vigente, permitindo antever de que forma poderiam traduzir-se na prática aqueles desideratos - que não raro assumem um caráter vago ou até mesmo obscuro - de "sensibilização da razão instrumental" (Marcuse), de "reincorporação do momento mimético" (Adorno) e de "reencantamento da ciência” (Serge Moscovici), sem por isso deixar de considerar como decisiva, para tal transformação, a efetiva participação de fatores extrínsecos à ciência, sejam eles sociais, econômicos ou ambientais, como julgamos ter deixado claro. 
Maurício Chiarello

Instituto de Filosofia e Ciências Humanas, Universidade Estadual de Campinas, Brasil. mauricio.chiarello@yahoo.com.br

\title{
The fascination of technological compulsion: on scientific rationality in Hans Jonas
}

\begin{abstract}
To what extent does the proposed new ethics for technological civilization, developed by Hans Jonas, have the power to convene scientists for the effective exercise of their responsibility to nature that is under threat? Does not the clarification, which his work is intended to further about the growing dangers associated with technical and scientific progress, seek basically to restrain, as a matter of emergency, the blind technological compulsion that leads to the perverse effects associated with technologizing and commercializing science today? Indeed, his critique of the legitimating ideology of techno-scientific progress ultimately intends to overcome the compulsive process of technological application, considered perverse in itself, that does not allow that other forms of techno-scientific progress could be developed that would become able to attend effectively to human, social and environmental values. Starting from the explanation of the impasses to which Jonas' proposal leads, we based ourselves on studies of Hugh Lacey in order to present an alternative way of structuring scientific activities. Aiming to overcome these impasses, we investigate to what extent the desired attention to moral, social and environmental values by current scientific and technological practices could be connected to an aesthetic experience that is able to provide openness to otherness and the reception of foreign values. Investigating the contribution of an experience of this kind is conducted in the light of thought motifs of Theodor Adorno and Herbert Marcuse.
\end{abstract}

KeYwords • Jonas. Domination of nature. Technoscience. Control. Values. Aesthetic experience. Mimesis. Lacey. Adorno. Marcuse.

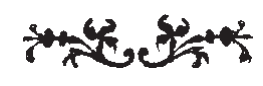


A fascinação da Gompulsão tegnológiga...

\section{REFERÊNGIAS BIBLIOGRÁFIGAS}

Adorno, W. Teoria estética. Tradução A. Morão. São Paulo: Martins Fontes/Edições 7o, 1988.

. Dialética negativa. Tradução M. A. Casanova. Rio de Janeiro: Zahar, 2009.

Adorno W. \& Horkheimer, M. Dialética do esclarecimento:fragmentos filosóficos. Tradução G. A. de Almeida.

Rio de Janeiro: Zahar, 1985 .

Feenberg, A. Critical theory of technology. New York: Oxford University Press, 1991.

Heidegger and Marcuse: the catastrophe and redemption of technology. New York: Routledge, 2004.

Freitas, V. Adorno e a arte contemporânea. Rio de Janeiro: Zahar, 2003.

Jonas, H. Évolution et liberté. Paris: Payot \& Rivages, 2000a.

. Une éthique pour la nature. Paris: Desclée de Brouwer, 2000b.

. O princípio vida: fundamentos para uma biologia filosófica. Petrópolis: Vozes, 2004.

. O princípio responsabilidade: ensaio de uma ética para a civilização tecnológica. Rio de Janeiro: Editora

Puc-Rio/Contraponto, 2006.

. Matéria, espírito e criação: dados cosmológicos. Tradução W. E. S. Lopes. Petrópolis: Vozes, 2010.

Lacey, H. Valores e atividade científica. São Paulo: Discurso Editorial, 1998.

. Ciência, respeito à natureza e bem-estar humano. Scientiae Studia, 6, 3, p. 297-327, 2008.

. Valores e atividade científica 2. São Paulo: Editora 34/Associação Filosófica Scientiae Studia, 2010.

Leite, M. Promessas do genoma. São Paulo: Editora Unesp, 2006.

Lories, D. \& Depré, O. Vie et liberté: phénoménologie, nature et éthique chez Hans Jonas. Paris: Vrin, 2003.

Marcuse, H. La nueva sensibilidad. In: . Un ensayo sobre la libertación. México: Joaquín Mortíz, 1969. p. $3 \circ-53$.

. Natureza e revolução. In: Contra revolução e revolta. Rio de Janeiro: Zahar, 1973. p. 63-80.

. Eros e civilização: uma interpretação filosófica do pensamento de Freud. Rio de Janeiro: LTC, 1999.

Oliveira, M. B. Neutralidade da ciência, desencantamento do mundo e controle da natureza. Scientix Studia, 6, 1, p. 97-116, 2008.

Pisani, M. M. Algumas considerações sobre ciência e política no pensamento de Herbert Marcuse. Scientix Studia, 7, 1, p. 135-58, 2009.

SAFatle, V. Espelhos sem imagens: mimesis e reconhecimento em Lacan e Adorno. Trans/Form/Ação, 28, 2, p. 21-45, 2005.

Tibaldeo, R. F. Hans Jonas' gnosticism and modern nihilism, and Ludwig von Bertalanffy. Philosophy and Social Criticism, 38, 3, p. 289-311, 2012.

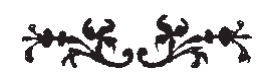

